\title{
LABORATORY-SCALE PRODUCTION OF COMMERCIAL GRADE CALCIUM CARBONATE FROM LIME-SODA PROCESS
}

\author{
M. S. Islam* and A. K. M. A. Quader \\ Department of Chemical Engineering, Bangladesh University of Engineering \& Technology, Dhaka-1000, Bangladesh
}

Received 20 May 2008; received in revised form 17 June 2008

\begin{abstract}
Quality precipitated calcium carbonate has much demand in various chemical and allied industries as filler, surface coating, whitening, adhesive etc. A study was carried out by modifying classical lime-soda process to obtain high quality precipitated calcium carbonate. The experiments were carried out in two stages using commercial and analytical grades of sodium carbonate and lime as reactants. After causticization, the filtrates from the washing of calcium carbonate were used to prepare all solutions for reactions in next stage. The precipitated calcium carbonate obtained from the process was analyzed and comparisons were made with the commercially available precipitated calcium carbonate produced from carbonation method. The calcium carbonate produced from causticization was superior to those produced by carbonation method in the country. The crystal structure of carbonate was calcite.
\end{abstract}

Keywords: Causticization; Settle Volume; Bulk Density; Yield.

\section{INTRODUCTION}

Precipitated calcium carbonate is one of the most versatile mineral fillers and is used in a wide range of products including paper, paint, plastic, rubber, ink, textiles, chalks, sealants, adhesives etc. United States Pharmacopoeia (USP) grades are used in dentifrices, cosmetics, foods and pharmaceuticals. Crescent Chemicals Ltd. and Usha Chemicals Ltd. are the producers of precipitated calcium carbonate in Bangladesh. The total production capacity of these plants is 20,000 tonnes per year against yearly consumption of 44,000 tonnes and the rest 24,000 tonnes per year of calcium carbonate is imported.

Precipitate Calcium carbonate can be produced by several methods such as [1]:

a. Carbonation Method

b. Calcium Chloride-Sodium Carbonate Double Decomposition Method

c. Lime-Soda Method

The carbonation method is the unique method of calcium carbonate production to-day and is widely used commercially.

The lime-soda process is the classical method of producing caustic soda. In this process, a solution of sodium carbonate is treated with excess calcium hydroxide producing liquid caustic and byproduct precipitated calcium carbonate. The quality of precipitated calcium carbonate formed in this process is not good replacement of commercial precipitated calcium carbonate. The byproduct calcium carbonate is handled in three following different ways [2]:

- "reburned" in rotary kilns to recover lime
- $\quad$ sent to cement plant for use as one of its main raw materials of cement

- disposed as waste when it cannot be sold or used

The present yearly demand for caustic soda and chlorine in Bangladesh are 80,000 tonnes and 3600 tonnes respectively. The demand for chlorine is being met locally while the production capacity of caustic soda in the country is only 20,000 tonnes per year. The rest 60,000 tonnes of caustic soda per year are imported [3]. Because of limited demand of chlorine, the growth of chlor-alkali industry in Bangladesh has been stopped. Considering reality (attractive demand of caustic soda and calcium carbonate) in Bangladesh, lime-soda process can be the right route for making caustic soda as it requires less investment per unit capacity.

The profitability of lime-soda process can be made attractive by improving the quality of the byproduct precipitated calcium carbonate and its efficient recovery. White colour, low alkalinity, free from harmful impurities and non abrasiveness are some prime requisites of calcium carbonate for use as a whitening, filler and coating. If byproduct precipitated calcium carbonate can be produced in such form by modification of the conventional process, the process can be commercially exploited.

This paper deals with obtaining quality precipitated calcium carbonate from modified limesoda process which involves two stage reaction for completing conversion of soda ash to caustic soda.

\section{EXPERIMENTAL}

Causticization was carried out in the laboratory by using both analytical and commercial grades of

*To whom all correspondence should be addressed.

(e-mail: shahinoorislam@che.buet.ac.bd) 
lime and sodium carbonate as reactants. The assay of analytical and commercial grades of lime and sodium carbonate are shown below in Tables 1 to 4 . A series of batch reactions were performed keeping lime as limiting reactant in the first stage for each batch. In second stage, sodium carbonate was the limiting reactant by having excess lime.

Table 1: Assay of Analytical Grade Soda Ash

\begin{tabular}{|l|l|}
\hline Component & Percent \\
\hline $\mathrm{Na}_{2} \mathrm{CO}_{3}$ & $\leq 99.5-100.5$ \\
\hline Chloride $\left(\mathrm{Cl}^{-}\right)$ & $\leq 0.0125$ \\
\hline Sulphate $\left(\mathrm{SO}_{4}{ }^{-}\right)$ & $\leq 0.025$ \\
\hline Arsenic $(\mathrm{As})$ & $\leq 0.001$ \\
\hline Lead $(\mathrm{Pb})$ & $\leq 0.0005$ \\
\hline Iron $(\mathrm{Fe})$ & $\leq 0.005$ \\
\hline
\end{tabular}

Table 2: Assay of Analytical Grade Calcium Oxide

\begin{tabular}{|l|l|}
\hline Component & Percent \\
\hline $\mathrm{CaO}$ & $\geq 97$ \\
\hline Chloride $\left(\mathrm{Cl}^{-}\right)$ & $\leq 0.05$ \\
\hline Sulphate $\left(\mathrm{SO}_{4}{ }^{-}\right)$ & $\leq 0.5$ \\
\hline Insoluble in $\mathrm{HCl}$ & $\leq 0.1$ \\
\hline Lead $(\mathrm{Pb})$ & $\leq 0.005$ \\
\hline Iron $(\mathrm{Fe})$ & $\leq 0.05$ \\
\hline
\end{tabular}

Table 3: Assay of Commercial Grade Soda Ash

\begin{tabular}{|l|l|}
\hline Component & Percent \\
\hline $\mathrm{Na}_{2} \mathrm{CO}_{3}$ & $\leq 95.00$ \\
\hline Moisture & 4.00 \\
\hline
\end{tabular}

Table 4: Assay of Commercial Grade Slaked Lime

\begin{tabular}{|l|l|}
\hline Component & Percent \\
\hline $\mathrm{Ca}(\mathrm{OH})_{2}$ & 93.00 \\
\hline $\mathrm{CaCO}$ & 3.00 \\
\hline $\mathrm{Moisture}$ & 1.00 \\
\hline $\mathrm{SiO}_{2}$ & 0.40 \\
\hline $\mathrm{Mg}$ & 0.59 \\
\hline $\mathrm{Fe}$ & 0.01 \\
\hline $\mathrm{CO}_{2}$ & 1.50 \\
\hline Dead burnt lime & 0.50 \\
\hline
\end{tabular}

A two-litre three necked round bottom heat resistant glass flask was used as causticizer. The size of the central neck was $45 / 40 \mathrm{~mm}$ and the other two side necks were $32 / 29 \mathrm{~mm}$. The stirrer was fitted through the central neck of the flask and was driven by an electric motor. Calcium hydroxide was kept in suspension by agitation. The other two necks were used to place condenser and thermocouple. Rubber stoppers with provision for installing stirrer, condenser and thermocouple were placed on the necks.
Two-stage causticization for both analytical and commercial grade reactants was performed in the laboratory. First stage was carried out keeping lime at $90 \%$ of its stoichiometric amount while the second stage was performed with $50 \%$ excess lime. In the initial batch $12.5 \%$ sodium carbonate solution was prepared by taking $105 \mathrm{~g}$ available soda ash in $735 \mathrm{ml}$ water in a beaker. For subsequent batches the first washed solution of both stage obtained from this batch was recycled and fresh sodium carbonate was added into the recycle stream as makeup. The amount of calcium oxide was charged as described earlier. Each stage of causticization is followed by decantation, vacuum filtration, analysis of product caustic soda, and drying and analyzing of calcium carbonate.

The reactants were charged through the neck fitted with thermocouple by taking it out. Cooling water was supplied countercurrently to condenser. The causticizer was sealed (using stirrer, condenser, and thermocouple in three necks) and the stirrer was then switched on. Heating of solution was started by keeping switch on of electro-mantle to raise the temperature of the solution at $90^{\circ} \mathrm{C}$ and it was maintained for $2.5 \mathrm{hrs}$. The pressure in the causticizer was maintained at atmospheric pressure by keeping the top of condenser open. After causticization for the stipulated time, the stirrer and heating mantle were switched off and the stirrer, thermocouple and condenser were removed from the flask and the valve for condenser cooling water was closed. The slurry was then poured into a beaker for settling. The clear solution was decanted after completion of the settling of the slurry, and the thick dense slurry was sent to vacuum filtration to separate caustic solution from calcium carbonate precipitate. The clear solution and filtrate were collected, analyzed and amount of sodium carbonate in the solution was determined. Caustic solution from first stage was charged for second stage causticization using $50 \%$ excess lime to achieve maximum equilibrium conversion of sodium carbonate to caustic soda.

The byproduct calcium carbonate cake from each stage contains a substantial amount of caustic soda in its pore space. To recover caustic soda from calcium carbonate, it was washed thrice as shown in Figure 1.

The cake deposited on the filter paper from last washing stage was dried in an electric oven. Initially cake was placed on tray with filter paper. The temperature of dryer was set at $100^{\circ} \mathrm{C}$ and the cake was kept at this condition for about an hour. The cake was then removed from filter paper and disintegrated manually. The cake was then dried for several hours at $110^{\circ} \mathrm{C}$. Finally, the calcium carbonate thus obtained was analyzed. The laboratory work undertaken to complete the causticization in a batch process is schematically shown in Figure 1. 


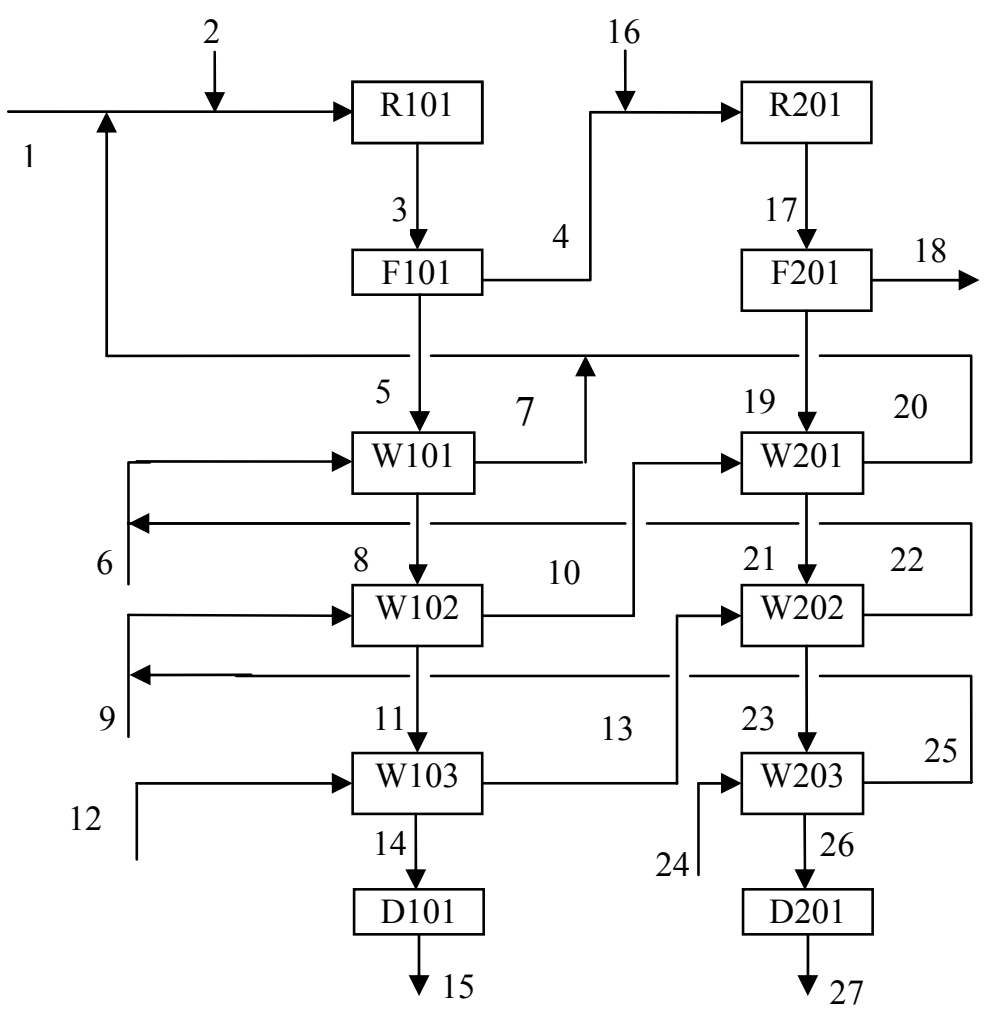

Figure 1: Block Diagram for Experimental Setup Performed in the Laboratory to Carry Out Causticization Reaction in two-stage

1: $\quad$ Fresh sodium carbonate feed to reactor

2: $\quad$ Lime feed to reactor $(90 \%$ of

stoichiometric amount)

3: $\quad$ Total effluent from first causticizer

4: $\quad$ First stage product caustic solution

5: $\quad$ Byproduct calcium carbonate from stage 1

8: $\quad$ First washed calcium carbonate

7: $\quad$ First washed solution from stage 1 used as recycle stream for next batch

6/9/12: Fresh water to stage 1

10: $\quad$ Second washed solution from first stage

11: $\quad$ Second washed calcium carbonate

13: Third washed solution from first stage

14: $\quad$ Washed calcium carbonate

15: Dried calcium carbonate

16: Lime feed to second causticizer

17: $\quad$ Total effluent from second causticizer

18: $\quad$ Product sodium hydroxide from second stage

19: $\quad$ Byproduct calcium carbonate from stage 2
20: $\quad$ First washed solution from stage 2 used as recycle stream for next batch

22: $\quad$ Second washed solution from second stage

24: $\quad$ Fresh water feed to second stage

25: Third washed solution from second stage

26: Washed calcium carbonate from second stage

27: Dried calcium carbonate from second stage

R101: First causticizer

F101: First causticizer outlet filter

W101: First calcium carbonate washer after first causticizer

D101: First stage outlet calcium carbonate dryer

R201: Second stage causticizer

F201: Second stage outlet filter

W201: Second stage outlet calcium carbonate first washer

D201: Second stage outlet calcium carbonate dryer 


\section{RESULTS}

Table-5 provides conversions of lime and sodium carbonate, and overall conversion of sodium carbonate for two stage causticization reactions.

The calcium carbonate produced by this process was analyzed in the laboratory at Crescent Chemicals Ltd., Gazipur. Table-6 lists various measured parameters that determine the quality of precipitated calcium carbonate.
The commercial precipitated calcium carbonate produced by Crescent Chemicals Ltd. using carbonation method as well as calcium carbonate produced by this method was analyzed in the laboratory. Crystal structures were determined by chemical and Scanning Electron Microscope (SEM) method. The crystal structure of each product was found to be calcite. Table-7 shows these results. Figure-2 shows the Scanning Electron Microscopic view of calcite structure.

Table 5: Summary of Results Obtained for Conversions of Lime and Sodium Carbonate to Caustic Soda in Two Stage Causticization

\begin{tabular}{|l|l|l|l|l|}
\hline \multirow{2}{*}{$\begin{array}{l}\text { Grades of } \\
\text { Reactants }\end{array}$} & \multirow{2}{*}{$\begin{array}{l}\text { Stage } \\
\text { No }\end{array}$} & \multicolumn{2}{|c|}{ \% Conversion(to $\mathbf{N a O H})$} & $\begin{array}{l}\text { \% Overall Conversion(to } \\
\mathbf{N a O H} \text { ) }\end{array}$ \\
\cline { 3 - 5 } & & Basis: $\mathbf{C a O} / \mathbf{C a}(\mathbf{O H})_{\mathbf{2}}$ & Basis: $\mathbf{N a}_{\mathbf{2}} \mathbf{C O}_{\mathbf{3}}$ & Basis: $\mathbf{N a}_{\mathbf{2}} \mathbf{C O}_{\mathbf{3}}$ \\
\hline \multirow{2}{*}{ Analytical } & 1 & $94.8-95.1$ & $86.0-86.7$ & \multirow{2}{*}{94.0} \\
\cline { 2 - 5 } & 2 & $32.0-35.8$ & $49.0-55.2$ & \\
\hline \multirow{2}{*}{ Commercial } & 1 & $97.0-97.5$ & $87.6-87.8$ & \multirow{2}{*}{94.0} \\
\cline { 2 - 5 } & 2 & $22.0-30.0$ & $34.0-50.0$ & \\
\hline
\end{tabular}

Table 6: Analytical Results of Precipitated Calcium Carbonate Produced by Lime- soda Process

\begin{tabular}{|l|c|c|}
\hline & $\begin{array}{l}\text { Product Calcium Carbonate using } \\
\text { Analytical Grade Reactants }\end{array}$ & $\begin{array}{l}\text { Product Calcium Carbonate using } \\
\text { Commercial Grade Reactants }\end{array}$ \\
\hline Calcium Carbonate, \% & 98.30 & 96.67 \\
\hline Calcium Oxide, \% & 1.22 & 1.27 \\
\hline Iron $(\mathrm{Fe}), \mathrm{ppm}$ & 468 & 1073 \\
\hline Bulk Density, $\mathrm{g} / \mathrm{ml}$ & 0.784 & 0.579 \\
\hline Settle Volume, $\mathrm{ml} / \mathrm{min}$ & $8 / 25$ & $13 / 25$ \\
\hline Moisture, \% & 0.40 & 0.24 \\
\hline Colour & Brilliant White & White \\
\hline
\end{tabular}

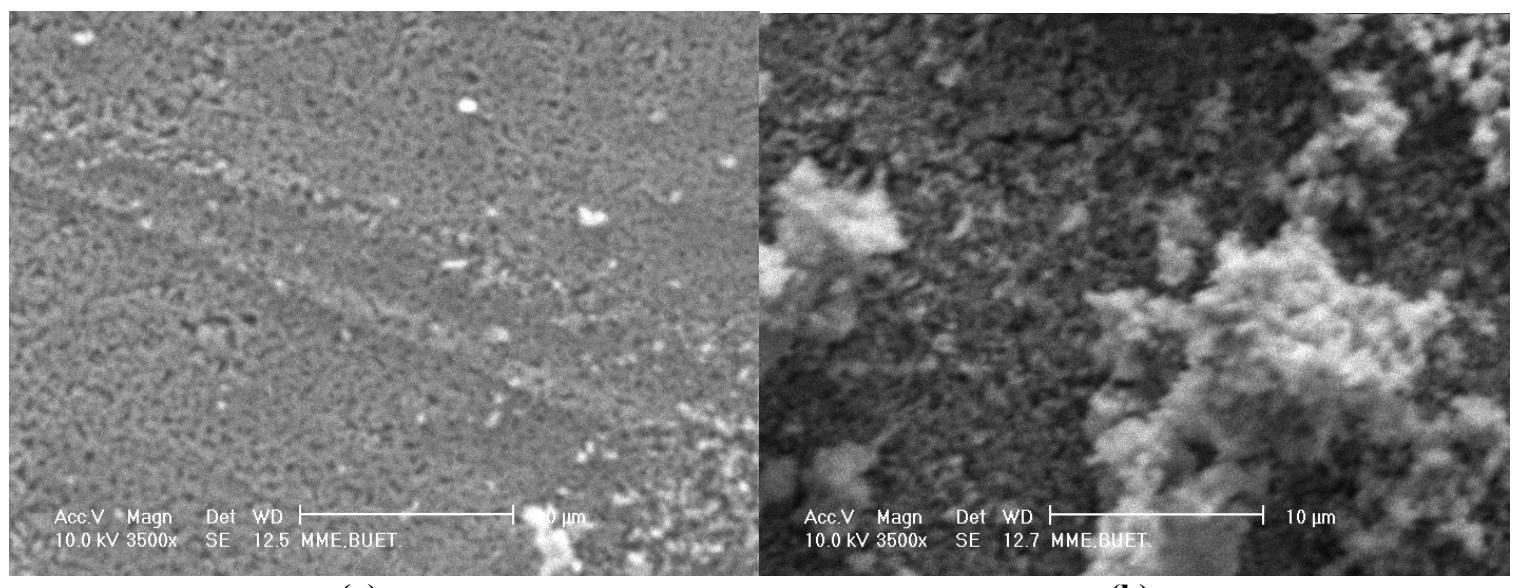

(a)

Figure 2: Calcite Crystal Structure of Precipitated Calcium Carbonate Determined by SEM Method; (a) Analytical Grade Reactants (b) Commercial Grade Reactants

Table 7: Analytical Results of Precipitated Calcium Carbonate in the Laboratory

\begin{tabular}{|l|l|l|l|}
\hline & $\begin{array}{l}\text { Product Calcium Carbonate } \\
\text { using Analytical Grade } \\
\text { Reactants }\end{array}$ & $\begin{array}{l}\text { Product Calcium Carbonate } \\
\text { using Commercial Grade } \\
\text { Reactants }\end{array}$ & $\begin{array}{l}\text { Commercial } \\
\text { Calcium } \\
\text { Carbonate }\end{array}$ \\
\hline Calcium Carbonate, \% & $98.3-99$ & $96.2-97$ & 97.06 \\
\hline Calcium Oxide, $\%$ & $0.2-0.4$ & $0.3-0.4$ & 0.375 \\
\hline Crystal Structure & Calcite & Calcite & Calcite \\
\hline
\end{tabular}


Table 8: Comparison of Laboratory Produced $\mathrm{CaCO}_{3}$ with Commercial Grade

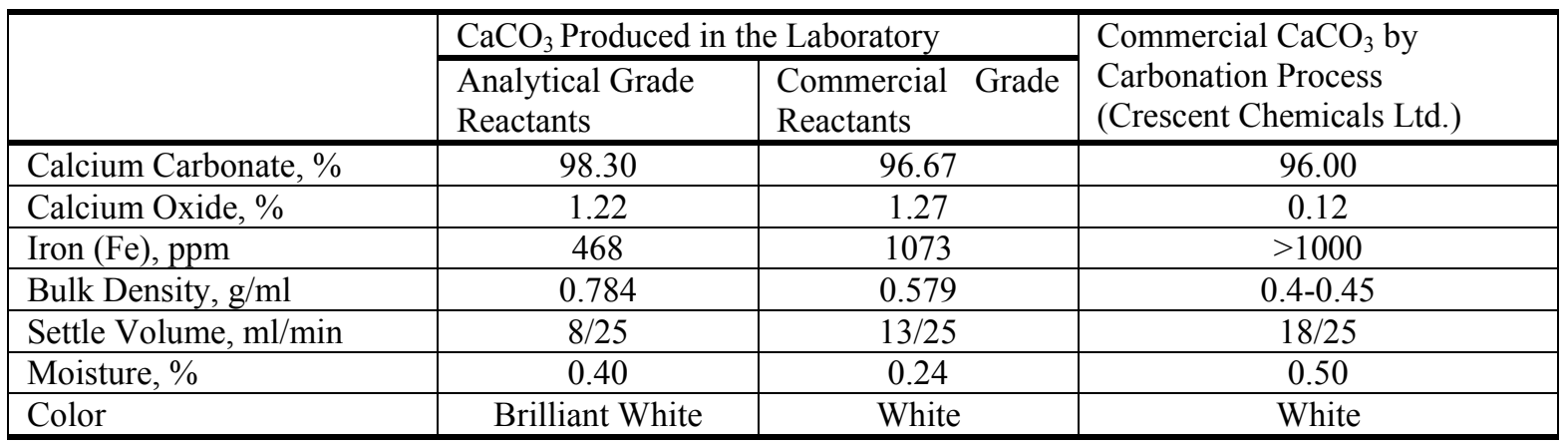

\section{DISCUSSION}

This work was concerned with enhancing conversion of sodium carbonate by adopting multistage operations. In practice, $12.5 \%$ sodium carbonate solution is used in industry to produce caustic soda and equilibrium conversion of this concentration is about $94 \%$. But the average conversion in single stage causticization is not much over $90 \%$. Hence the first stage of causticization was carried out with $90 \%$ stoichiometric amount of lime. The purpose of performing this stage was to get $100 \%$ conversion of lime i.e., to get high quality precipitated calcium carbonate. In the case of commercial grade reactants, dry calcium hydroxide and sodium carbonate were used to carry out causticization and the conversion from first stage was about $97.5 \%$, but that for analytical grade was about $95 \%$. The reagent grade quick lime used was from an old stock. The exact physical state of the lime was unknown. What has led to conversion lower than expected (calculated) is difficult to explain. But the overall conversion found from each grade was about $94 \%$, remained same for each type of reagent. The commercial precipitated calcium carbonate produced by Crescent Chemicals Ltd. as well as calcium carbonate produced from this method was analyzed in the laboratory. Crystal structures determined by chemical method of each product were found calcite which was also observed by Scanning Electron Microscope (SEM) method. Figure-2 shows the Scanning Electron Microscopic view of calcite structure. The analysis of byproduct calcium carbonate was carried out in the laboratory at Crescent Chemicals Ltd. Table-6 shows result of this analysis and Table- 8 shows comparison among produced calcium carbonate by present study to commercial precipitated calcium carbonate produced at Crescent Chemicals Ltd. For analytical grade reactants, the calcium carbonate percent was found about $98.3 \%$ as against $96.67 \%$ for commercial grade reagents.

Table 7 shows the laboratory analysis of precipitated calcium carbonate produced by carbonation and lime-soda process. The result clearly indicates the quality of product precipitated calcium carbonate obtained from both methods is identical. The calcium oxide content was same for each grade of product.

The bulk density of product calcium carbonate obtained from this process was higher than the product obtained by commercial carbonation process. Presence of Iron, settle volume, colour, etc also affect quality of calcium carbonate.

The bulk density is very important criteria of precipitated calcium carbonate for consuming the product in paper, plastic, ceramic, rubber industries etc. The major problem of in commercial processes is low bulk density of their product calcium carbonate. As a result they can not expand their market in those sectors like paper making industries where high bulk density is the prime requisite of precipitated calcium carbonate. The colour of the product calcium carbonate was also white.

Calcium carbonate occurs in nature either of two polymorphs: calcite or aragonite. The crystal form of calcite is hexagonal form and aragonite is in orthorhombic system. In the commercial forms of precipitated calcium carbonate, where aragonite predominates, crystals have parallel sides and large length to width ratios.

The production of caustic soda from lime-soda process is not cost effective if it is produced using conventional one stage process. The conventional one-stage process may be replaced by present twostage lime-soda process. In present lime-soda process, the byproduct calcium carbonate is highly pure, comparable with commercially available calcium carbonate. The byproduct calcium carbonate has a great demand in various industries as filler, coating, adhesive etc., so this two stage lime-soda process may play an important role in partial fulfilling the demand of caustic soda and calcium carbonate. Marketing of this quality byproduct calcium carbonate will improve the economic viability of lime-soda process in Bangladesh. Thus, Multi-stage causticization can pave the way for achieving equilibrium conversion of sodium carbonate to sodium hydroxide as well as obtaining purer calcium carbonate in the first stage by using lime as the limiting reactant. 


\section{CONCLUSION}

The by-product calcium carbonate obtained from this modified process was pure. The quality of this product was comparable with the commercially available precipitated calcium carbonate produced by carbonation method. In the case of analytical grade reactants, the calcium carbonate produced was $98.3 \%$, which was $96.67 \%$ for commercial grade reactants. The crystal structure of precipitated calcium carbonate was found to be calcite.

\section{REFERENCES}

1. Kirk-Othmer Encyclopedia of Chemical Technology, $3^{\text {rd }}$ Ed. 1978, Wiley Interscience Publication.
2. Hou, T.P., Manufacture of Soda, $2^{\text {nd }}$ ed. 1969 , New York: Hafner Publishing Company.

3. Prasadi, U. K., Caustic - Chlorine Industries of Bangladesh. 2006, Dhaka.

4. Islam, M.S., A Study for Enhancing Yield of Caustic Soda in Causticization Reaction for Industrial Application in Department of Chemical Engineering. M.Sc. Engineering Thesis, 2007, Bangladesh University of Engineering \& Technology, Dhaka. 